\title{
Assessment of Knowledge of Neonatal Jaundice among Mothers Attending Maternal and Pediatric Hospital in Soran City
}

\author{
Kareem Jamal Hamad*, Haroon Muhammad Khalil \\ Department of Nursing, Erbil Polytechnic University, Soran Technical Institute, Erbil, Iraq
}

\section{${ }^{*}$ Corresponding author: Kareem Jamal Hamad, Department of Nursing, Erbil Polytechnic University, Soran Technical Institute, Erbil, Iraq. \\ E-mail: Kareem.hamad@epu. edu.iq}

Received: 17 April 2018

Accepted: 04 September 2018

Published: 30 June 2019

DOI

10.25156/ptj.v9n1y2019.pp32-36

\section{A B S T R A C T}

Neonatal jaundice is one of the most common and serious conditions requiring medical attention. Early discharge of neonates before the onset of jaundice would reduce access to treatments and mothers act critical role in managing condition. Therefore, this study set out to assess the mothers' knowledge of neonatal jaundice. A descriptive study was conducted from January to May 2018, using random sample of 100 mothers attended maternal and pediatric hospital in Soran city during antenatal visit. Data were collected through the use of a specially designed questionnaire for the purpose of the study. The finding of the study shows that $36 \%$ of mothers were in the age group of $25-30$ years. Majorities (84\%) were Muslim, $76 \%$ of them were housewives, and $49 \%$ was multipara. Another major finding revealed that most of the mothers $(88 \%)$ had poor knowledge of neonatal jaundice. Results show a significant association between education level, occupation of mothers, and their knowledge of neonatal jaundice. This study revealed that mothers had poor knowledge and there was a dramatic lack of knowledge regarding causes and danger signs of neonatal jaundice. Education level and occupation status had a significant impact on mothers' knowledge. It is recommended more attention on educating mothers during antenatal visits, as well as proper training health-care providers, updating their knowledge and teaching methods.

Keywords: Assessment; Knowledge; Mother; Neonatal jaundice

\section{INTRODUCTION}

Neonatal jaundice is a common condition worldwide. Studies reported that approximately all preterm babies and more than $60 \%$ of term newborns were developing jaundice in the $1^{\text {st }}$ week of their life and their requiring medical attention.

Neonatal morbidity and mortality is still high in developing countries, especially in African, Asian, and Latin American, of which one of the most important contributing factors is jaundice (Behrman et al., 2004). Neonates' experience different problems from which, hyperbilirubinemia or jaundice is very common, life threatening and challenging are high (Neghabadi et al., 2015). National Collaborating Centre for Women's and Children's Health, 2010 mentioned neonatal jaundice as yellow coloration of the skin and the sclera in newborn babies that result from accumulation of bilirubin in the skin and mucous membranes.

The changing color of the skin and sclera is a result of excess bilirubin in which is produced by the normal breakdown of red blood cells. Normally, bilirubin passes through the liver and is excreted as bile through the intestines. Jaundice occurs when bilirubin builds up faster than a newborn's liver can break it down and pass it from the body. This is associated with a raised level of bilirubin $>85 \mu \mathrm{mol} / 1(5 \mathrm{mg} / \mathrm{dl})$ in the circulation, a condition known as hyperbilirubinemia (Aiswarya and Sajeeth, 2016), (National Collaborating Centre for Women's and Children's Health, 2010).

The effects of jaundice are often irreversible including lethargy, poor feeding, high pitched cry, seizures, hearing loss, cerebral palsy, and mental retardation (Dennery et al., 2001). Neonates may be sent home with their mothers earlier than the time of onset of jaundice, which would reduce access to treatments. It may be viewed as a normal finding, especially in regions that it commonly occurs, and this may delay treatment as well (Vaez, 2016).

Mothers should be adequately educated about the care of baby with jaundice and early identification of danger signs and also its complications (Dash, 2013).

There is no information available on how mothers deal with neonatal jaundice and their awareness for this 
subject. Therefore, determining the level of mothers' knowledge and awareness regarding neonatal jaundice is of importance, to reduce the risk for future babies to develop jaundice, for early intervention and treatment (Kamara, 2014).

The purpose of the present study is to find out what mothers know about neonatal jaundice, including jaundice presentation sites, danger signs, causes, complications, diagnosis ways, and effective treatments. The information and findings will be used to improve health education and raising the mothers' knowledge and awareness.

\section{SUBJECTS AND METHODS}

A descriptive study design was carried out in maternal and pediatric hospital in Soran city of Erbil Governorate. The study conducted between the periods of January and May 2018 on a sample of 100 mothers selected by simple random sampling technique (each individual was chosen randomly and entirely by chance, such that each individual had the same probability of being chosen during the sampling process). All participants were informed about the purpose of the study. Verbal consent was taken from participants, and severe sick, mentally handicapped, those with difficulty in communication and mothers who refused participation were excluded from the study. Data were collected using a specially designed questionnaire by the researcher. Participants were interviewed by three trained investigator under the supervision of author, avoiding interpersonal communication on the study and preventing any influence on response from the respondent during the interview period. Questionnaire consists of two parts: Part I related to sociodemographic characteristics (including age, gender, occupation, and education levels) and parity. Part II related to mothers' knowledge of neonatal jaundice (including presentation sites, danger signs, causes, complications, ways of diagnosis, and effective treatments). Categorical responses yes, no, and do not know were applied for the question items. One point awarded for each correct answer and zero for incorrect or do not know. Total knowledge scores for each participant calculated by summation of correct responses with range of $0-22$ which divided into three categories of poor knowledge (score $\leq 6$ ), average knowledge (score 7-13), and good knowledge (score $\geq 14$ ). The Statistical Package for the Social Sciences (SPSS, version 15) was used to compute frequencies and association of different variables. Chi-square analysis was used to identify any kind of association between different variables in the study. ( $P \leq 0.05$ was considered statistically significant).

\section{RESULTS}

\section{Sociodemographic Characteristics of the Study Sample}

In the present study as shown in Table $1,36 \%$ of mothers were within the age group of 25-30 years old. Majority (84\%) of the mothers were of Muslim religion. Regarding education level, highest percentage $(31 \%)$ of mothers was illiterate followed by $23 \%$ and $23 \%$ were university/institute and secondary, respectively. In regard to occupation, majority of mothers $(76 \%)$ were housewife. Results indicate that near to half $(49 \%)$ of participants were multipara followed by $43 \%$ who were primipara as shown in Table 1.

\section{Knowledge of Mothers about Neonatal Jaundice}

As it is shown in Table 2, the knowledge of mothers classified into three levels, majority $(88 \%)$ of them had poor knowledge on neonatal jaundice while only $12 \%$ had average level of knowledge.

\begin{tabular}{|c|c|c|}
\hline Sociodemographic characteristics & Number & $\%$ \\
\hline \multicolumn{3}{|l|}{ Age } \\
\hline$<25$ & 17 & 17 \\
\hline $25-30$ & 36 & 36 \\
\hline $31-40$ & 24 & 24 \\
\hline$>40$ years & 23 & 23 \\
\hline \multicolumn{3}{|l|}{ Religion } \\
\hline Muslim & 84 & 84 \\
\hline Christians & 13 & 13 \\
\hline Others & 3 & 3 \\
\hline \multicolumn{3}{|l|}{ Education level } \\
\hline Illiterate & 31 & 31 \\
\hline Primary & 22 & 22 \\
\hline Secondary & 23 & 23 \\
\hline University/institute & 23 & 23 \\
\hline Postgraduate & 1 & 1 \\
\hline \multicolumn{3}{|l|}{ Occupation } \\
\hline Student & 5 & 5 \\
\hline Government employee & 11 & 11 \\
\hline Private sector worker & 7 & 7 \\
\hline Retired & 1 & 1 \\
\hline Housewife & 76 & 76 \\
\hline \multicolumn{3}{|l|}{ Parity } \\
\hline 0 & 8 & 8 \\
\hline Primipara & 43 & 43 \\
\hline Multipara & 49 & 49 \\
\hline
\end{tabular}

Table 2: Distribution of sample by the level of knowledge of neonatal jaundice

\begin{tabular}{lcc}
\hline Knowledge level & Category score & $\%$ \\
\hline Poor knowledge & $\leq 6$ & 88 \\
Average knowledge & $7-13$ & 12 \\
Good knowledge & $14-22$ & 0 \\
\hline
\end{tabular}


Results show $58 \%$ of mothers known that neonatal skin is presentation site of jaundice followed by half of sample was known sclera. Very limited scores were achieved in dangers of neonatal jaundice, the results show that nobody in the sample had information about arching of the back is danger, and only $4 \%$ of them known down rolling of eyes is a one danger.

Mothers' knowledge of the causes of neonatal jaundice was very low and only $13 \%$ of the mothers were aware of prematurity. Concerning complication of severe neonatal jaundice, $45 \%$ of sample indicated neonatal death, followed by $6 \%, 5 \%$, and $3 \%$ were reported in seizure, brain injury (kernicterus), and mental retardation, respectively. Results show that $41 \%$ of mothers indicated to appearance as the best way of diagnosis and more than half of them $(56 \%)$ knew that phototherapy was a form of the treatment for neonatal jaundice as shown in Table 3.

Results revealed statistically significant association between education level $\left(\chi^{2}=15.894, P=0.003\right)$, occupation $\left(\chi^{2}=13.478, P=0.019\right)$, and knowledge levels of mothers on neonatal jaundice. Findings of the study show no significant association between knowledge levels with age

Table 3: Knowledge of mothers about neonatal jaundice

\begin{tabular}{|c|c|}
\hline Items & $\%$ \\
\hline \multicolumn{2}{|l|}{ Presentation sites of neonatal jaundice } \\
\hline Sclera & 50 \\
\hline Palm and sole of foot & 12 \\
\hline Neonate skin & 58 \\
\hline \multicolumn{2}{|l|}{ Danger signs of neonatal jaundice } \\
\hline Refusal to feed & 16 \\
\hline High pitched cry & 12 \\
\hline Arching of the back & 0 \\
\hline Down rolling of eyes & 4 \\
\hline Fever & 28 \\
\hline Seizure & 9 \\
\hline \multicolumn{2}{|l|}{ Causes of neonatal jaundice } \\
\hline Blood group incompatibility & 2 \\
\hline Infection in blood (septicemia) & 3 \\
\hline Prematurity (low birth weight) & 13 \\
\hline \multicolumn{2}{|c|}{ Complication of severe neonatal jaundice } \\
\hline Neonatal death & 45 \\
\hline Brain injury (kernicterus) & 5 \\
\hline Mental retardation & 3 \\
\hline Seizure in future & 6 \\
\hline \multicolumn{2}{|c|}{ The best way of diagnosis neonatal jaundice } \\
\hline Urine analysis & 9 \\
\hline Blood analysis & 19 \\
\hline Appearance & 41 \\
\hline \multicolumn{2}{|l|}{ Effective treatment } \\
\hline Phototherapy & 56 \\
\hline Blood exchange in severe cases & 7 \\
\hline Use of drugs & 35 \\
\hline
\end{tabular}

$\left(\chi^{2}=1.633, P=0.656\right)$, religion $\left(\chi^{2}=2.051, P=0.355\right)$, and parity $\left(\chi^{2}=1.249, P=0.536\right)$ as shown in Table 4 .

\section{DISCUSSION}

The present study revealed that more than half of mothers indicated skin and sclera as presentation sites of neonatal jaundice. Similar findings were also reported by Adeeb et al., 2016; Alemu et al., 2011; and Khalesi and Rakhshani, 2008. The finding in this study revealed that majority of mothers were unaware of danger signs of neonatal jaundice; however, $28 \%$ of respondents indicated fever and $16 \%$ opined refusal to feed while nobody in the sample had information about arching of the back as danger. These results agree with those of a study done in Iran, in which mothers selected refusal of feed and fever as danger signs (Khalesi and Rakhshani, 2008) while another study on knowledge of mothers in immunization clinic at a tertiary care hospital of Lucknow, India, by Shukla and Agarwal (2016) discovered the rate of $51 \%$ for refusing of feed, $68.7 \%$ for fever, and $32 \%$ high pitched cry.

Results show poor knowledge of the causes of neonatal jaundice among participants, similar findings revealed in a study in Nigeria by Opara et al. (2014). In contrast to these findings, in a study in India, about half of mothers answer prematurity as the major cause of neonatal jaundice by Shukla and Agarwal (2016). The present study shown that $45 \%$ of mothers expected neonatal death as result of severs neonatal jaundice, while the rate was $6 \%$ for seizure, $5 \%$ brain injury (kernicterus), and 3\% for mental retardation.

Concerning the complications, the present study was in agreement with findings of Shukla and Agarwal, 2016; Aggarwal et al., 2017; and Egube et al., 2013, while quite a different finding was noticed in a study of Khalesi and Rakhshani (2008) carried out in Iran.

In terms of diagnosis, findings of the present study demonstrated that less than half of mothers answered appearance, and one-fifth indicated blood analysis as a method of diagnosis jaundice. In the present study, phototherapy and use of drugs, respectively, were reported by $56 \%$ and $35 \%$ as effective treatment for neonatal jaundice. Similar finding was reported by Huq et al., 2017, in Dhaka city, and with studies of Ahmed and Hani, 2017; Allahony et al., 2016; and Egube et al., 2013.

Number of studies carried out in different places such as Adebami, 2015, in Nigeria; Aggarwal et al., 2017, in India; Onyearugha et al., 2016, in Nigeria; and Dash, 2013, in India, all together consistence with low level of knowledge 
Table 4: Sociodemographic characteristics of respondents and their knowledge of NN jaundice

\begin{tabular}{|c|c|c|c|c|c|c|}
\hline \multirow[t]{3}{*}{ Variable } & \multicolumn{4}{|c|}{ Knowledge level } & \multirow[t]{3}{*}{ Chi-square $\left(\chi^{2}\right)$} & \multirow[t]{3}{*}{ p } \\
\hline & \multicolumn{2}{|c|}{ Poor knowledge } & \multicolumn{2}{|c|}{ Average knowledge } & & \\
\hline & $\mathbf{N}$ & $\%$ & $\mathbf{N}$ & $\%$ & & \\
\hline Age & & & & & 1.663 & 0.656 \\
\hline$<25$ & 16 & 94.1 & 1 & 5.9 & & \\
\hline $25-30$ & 31 & 86.1 & 5 & 13.9 & & \\
\hline $31-40$ & 22 & 91.7 & 2 & 8.3 & & \\
\hline$>40$ years & 19 & 82.6 & 4 & 17.4 & & \\
\hline \multicolumn{7}{|l|}{ Religion } \\
\hline Muslim & 75 & 89.3 & 9 & 10.7 & 2.051 & 0.355 \\
\hline Christians & 10 & 76.9 & 3 & 23.1 & & \\
\hline Others & 3 & 100 & 0 & 0 & & \\
\hline \multicolumn{7}{|l|}{ Education level } \\
\hline Illiterate & 28 & 90.3 & 3 & 9.7 & 15.894 & 0.003 \\
\hline Primary & 21 & 95.5 & 1 & 4.5 & & \\
\hline Secondary & 23 & 100 & 0 & 0 & & \\
\hline University/institute & 15 & 65.2 & 8 & 34.8 & & \\
\hline Postgraduate & 1 & 100 & 0 & 0 & & \\
\hline \multicolumn{7}{|l|}{ Occupation } \\
\hline Student & 5 & 100 & 0 & 0 & 13.478 & 0.019 \\
\hline Government employee & 8 & 72.7 & 3 & 27.3 & & \\
\hline Private sector worker & 5 & 71.4 & 2 & 28.6 & & \\
\hline Retired & 0 & 0 & 1 & 100 & & \\
\hline Housewife & 70 & 92.1 & 6 & 7.9 & & \\
\hline \multicolumn{7}{|l|}{ Parity } \\
\hline 0 & 8 & 100 & 0 & 0 & 1.249 & 0.536 \\
\hline Primipara & 37 & 86 & 6 & 14 & & \\
\hline Multipara & 43 & 87.8 & 6 & 12.2 & & \\
\hline
\end{tabular}

regarding effective treatment of neonatal jaundice among respondents.

The present study revealed that majority (88\%) of participants had poor knowledge level regarding neonatal jaundice, especially in domains of causes and danger signs, and poor knowledge may adversely affect the mother actions and cause increase related morbidity and mortality. Our findings revealed that there was no association between mothers' knowledge level and age, agreed with the study of Aggarwal et al., 2017, and in contrast with studies of Mohini and Shetty, 2017; Ahmed and Hani, 2017; and Hussein and Aziz, 2016.

There was no association between religion and mothers' level of knowledge unlike the study of Aggarwal et al. (2017). The present study revealed that education level and occupation status significantly affected on scores of knowledge. These findings supported by the results of Mohini and Shetty, 2017, and Ogunlesi and Abdul, 2015, in Nigeria.

\section{CONCLUSION}

Based on the finding of the present study, it can be concluded that knowledge of neonatal jaundice among mothers was very low. The study revealed that lack of knowledge was significantly associated with educational level and occupation status of respondents. The study recommended that awareness and educational programs should be incorporated into serving the health services during antenatal visits and at the community level on all aspects of neonatal jaundice as well as further training courses, confirmation of the skills for health-care providers, and updating their knowledge and teaching methods.

\section{REFERENCES}

Adebami, O. 2015. Assessment of knowledge on causes and care of neonatal jaundice at the Nigerian primary and secondary health institutions. Int. J. Res. Med. Sci. 3: 2605-2612.

Adeeb, M., K. Kumarasamy, S. A. Hamid, N. Mahat, K. Arumugam and S. A. Shukor. 2016. Knowledge and attitude of neonatal jaundice orang asli perspective. J. Sains Kesihatan Malaysia. 14(2): 65-68.

Aggarwal, B., A. Agrawal, P. Chaudhary, G. Gupta, S. Rana and S. Gupta. 2017. Neonatal jaundice: Knowledge, attitude beliefs, and practices of postnatal mothers in a tertiary care hospital in Uttarakhand, India. Int. J. Child Health. 4(4): 603-608.

Ahmed, S. M. and M. Hani. 2017. Assessment of nurse's knowledge and practice working in district hospitals at minia governorate about neonatal hyperbilirubinemia. IOSR. J. Nurs. Health Sci. 6(2): 9-16. 
Aiswarya, A. T. and C. I. Sajeeth. 2016. The incidence, risk factors and management of neonatal jaundice in a government hospital, Palakkad district, Kerala. Int. J. Health Sci. Res. 6(6): 123-129.

Alemu, S., S. Palani and N. Joseph. 2011. Knowledge, attitude and perception towards jaundice among ayder referral hospital health workers. Int. Res. J. Pharm. 2(12): 191-195.

Allahony, D., N. Hegazy, Z. Kasemy and E. Bahgat. 2016. Mothers' perception toward neonatal jaundice in Kafr el-batanoon village, Menoufia, Egypt. Menoufia Med. J. 29(3): 743-748.

Behrman, R., R. Kliegman and H. Jenson, editors. 2004. Nelson Text book of Pediatrics. $17^{\text {th }}$ ed. Saunders, Philadelphia, PA. p523-599.

Dash, M. 2013. A descriptive study to assess the knowledge and attitude on neonatal jaundice among the mothers in a selected village of Puducherry. Res. Rev. J. Med. Health Sci. 2(3): 41-46.

Dennery, P. A., D. S. Seidman and D. K. Stevenson. 2001. Neonatal hyperbilirubinemia. N. Engl. J. Med. 344: 581590.

Egube, B., A. Ofili, A. Isara and J. Onakewhor. 2013. Neonatal jaundice and its management: Knowledge, attitude, and practice among expectant mothers attending antenatal clinic at university of Benin teaching hospital, Benin city, Nigeria. Niger. J. Clin. Pract. 16(2): 188-194.

Huq, S., S. M. Hossain, S. M. T. Haque and M. A. Tarafder. 2017. Knowledge regarding neonatal jaundice management among mothers: A descriptive study done in a tertiary level hospital of Dhaka city. AKMMC J. 8(2): 121-127.

Hussein, H. S. A. and A. R. Aziz. 2016. Assessment of mothers' knowledge and beliefs toward care of neonatal jaundice in pediatric teaching hospital in Holy Karbala city. Int. J. Sci. Res. Publ. 6(9): 585-593.

Kamara, I. 2014. Factors Associated with Neonatal Hyperbilirubinemia in the First 2 Weeks of Life in Ola During Children's Hospital in Freetown, Sierra Leon. M.Sc. Thesis. University of Nairobi.
Khalesi, N. and F. Rakhshani. 2008. Knowledge, attitude and behaviour of mothers on neonatal jaundice. J. Pak. Med. Assoc. 58(12): 671-674.

Mohini, H. and B. S. Shetty. 2017. A study to assess the knowledge of mothers on home based neonatal care at selected area of rural Bangalore. Int. J. Community Med. Public Health. 4(5): 1695-1700.

National Collaborating Centre for Women's and Children's Health. 2010. Neonatal Jaundice. Clinical Guideline. Regent's Park, London, Published by the Royal College of Obstetricians and Gynaecologists.

Neghabadi, F. P., M. Nourian, S. A. Farahani, M. A. Pourhoseingholi and A. F. shoorideh. 2015. Auditing phototherapy-related nursing care in neonatal general and intensive care units. Iran. J. Crit. Care. Nurs. 8(3): 167-172.

Ogunlesi, T. A. and A. R. Abdul. 2015. Maternal knowledge and careseeking behaviors for newborn jaundice in Sagamu, Southwest Nigeria. Niger. J. Clin. Pract. 18(1): 33-40.

Onyearugha, C., A. Chapp-Jumbo and I. Georg. 2016. Neonatal jaundice: Evaluating knowledge and practice of expectant mothers in Aba, Nigeria. J. Health Sci. Res. 1( 2): 42-47.

Opara, P., B. Alex-Hart and D. Dotimi. 2014. Knowledge, attitude and practice towards neonatal jaundice among community health workers in Southern Nigeria. Int. J. Trop. Dis. Health. 4(11): 1171-1178.

Shukla, M. and M. Agarwal. 2016. Knowledge of mothers regarding neonatal jaundice attending immunization clinic at a tertiary care hospital of Lucknow. Int. J. Appl. Res. 2(6): 297-299.

Vaez, A. 2016. Knowledge and Attitudes of Mothers on Neonatal Jaundice in Saravan, Iran. Honors Thesis. Eastern Kentucky University. 